\title{
A Review of Two Nanocomposite Insulating Materials Models: Lewis' Contribution in the Development of the Models, their Differences, their Similarities and Future Challenges
}

\author{
M. G. Danikas \\ Democritus University of \\ Thrace, Department of \\ Electrical and Computer \\ Engineering, Xanthi, Greece \\ mdanikas@ee.duth.gr
}

\author{
A. Bairaktari \\ Democritus University of \\ Thrace, Department of \\ Electrical and Computer \\ Engineering, Xanthi, Greece \\ agbairaktari@gmail.com
}

\author{
R. Sarathi \\ Indian Institute of \\ Technology Madras, \\ Department of Electrical \\ Engineering, Chennai, India \\ rsarathi@gmail.com
}

\author{
A. Basri Bin Abd Ghani \\ TNB Research Sdn. Bhd., High \\ Voltage Cable Diagnostics, \\ Distribution Unit, Selangor, \\ Malaysia \\ abasri.aghani@tnbr.com.my
}

\begin{abstract}
Nanocomposite polymers are nowadays a major field of research. This paper investigates the interpretational possibilities of two models developed, namely, Tsagaropoulos' model and Tanaka's model. Particular emphasis is given to Lewis' model, which was the first one to be proposed and whose contribution to the aforementioned models was significant. The two models were developed separately and independently from each other. They both consider various layers around the nanoparticles. They both consider well bonded and more loosen layers. Similarities and differences between the two models are pointed out and discussed as well as possibilities for further research in order to shed light on some aspects of electrical phenomena in these materials. Particular emphasis is given to the interfaces between the nanoparticles and the surrounding base material. Comments are offered regarding the challenges facing the two models w.r.t. the interpretation of discharges on nanocomposite surfaces. Possible new areas of research are suggested and new challenges for the aforementioned models are pointed out.
\end{abstract}

Keywords - nanocomposites; nanoparticles; glass transition temperature; electrical trees; dielectric breakdown; breakdown strength; discharge path; surface discharge

\section{INTRODUCTION}

More than twenty years now researchers try to improve conventional polymers by adding minute particles (nanoparticles) into the polymer matrix, thus changing their electrical, mechanical and thermal properties [1-4]. There are by now practically hundreds (if not thousands) of publications regarding nanocomposites and their related properties $[5,6]$. As was remarked elsewhere among other things, "the emergence of a new class of dielectrics, ca. 2001 and first experimental data evidencing nanocomposites as dielectrics in 2002 stirred things up for the last decade" and "[although] nanodielectrics are not a panacea ... [they] have definitely a future" [7].
Of considerable interest is the subject as to why nanoparticles inserted into conventional polymers improve so dramatically the various properties of nanocomposites. The improvement may be due to the interfaces present because of the numerous nanoparticles. It is most certain that what is valid in conventional physics, is not necessarily valid for nanocomposites. Three of the most interesting models that have been developed w.r.t. the interpretation of some of the electrical properties and/or electrical phenomena in nanocomposites are the following: Lewis' model [1], Tsagaropoulos' model [8] (it was proposed especially as a possible explanation as to why nanocomposites show the behavior they do, regarding the glass transition temperature) and Tanaka's model, as a possibility to explain various phenomena, such as electrical treeing and dielectric breakdown in nanocomposites $[9,10]$. It is to be pointed out that Lewis' model was chronologically the first proposed.

A first approach of nanocomposites models developed was made in [11], where two of the models were analyzed. Parts of [11] are incorporated in the present paper, especially those that have to do with the description of Tsagaropoulos' and Tanaka's models. It is the aim of the present paper to analyze aspects of the two aforementioned models (Tsagaropoulos' and Tanaka's) as well as to compare them regarding their interpretational possibilities.

\section{THE ROLE OF NANOPARTICLE INTERFACES}

Interfaces play a critical role in classical insulating systems $[12,13]$. Their function is paramount to the good functioning of such systems, in such a way that some researchers claim that the problems of insulating materials are not but problems of interfaces. In the case, however, of the nanocomposites, their role, although it is extremely important, is not the same with that of classical interfaces. 
The role of interfaces has been pointed out in [1]. The improved properties of nanocomposites are due to the behavior of the interfacial interaction zone which surrounds the nanoparticles. The characteristics of the interfacial interaction zone are the following: 1) mobility, which depends on the physico-chemical bonds created on the common surface, and 2) formation at the interface of a double layer, which may affect the local conductivity. The effect of these two mechanisms is due to the considerable increase of the interfacial surface area [14]. In fact, the surface area formed by nanoparticles (and consequently the interfacial surface area) is three orders of magnitude larger than that of the microparticles [15].

Moreover, the Maxwell-Wagner polarization is not so evident in the case of the nanocomposites, as it is with conventional polymers. This is because of the size of the nanoparticles, which as they become too small, they do not present the Maxwell-Wagner polarization. Maxwell-Wagner polarization changes significantly as the dimensions of inserted particles approach the length of polymer chain [16]. With the addition of nanoparticles in a base polymer, the aforementioned mobility and the structure of the surrounding polymer change considerably. The nanoparticles have a large surface area and this is the reason as to why the interaction zones in a nanocomposite are much larger than in a conventional polymer or in a polymer containing microparticles. In [1], it is proposed that around the nanoparticles a Stern layer and a diffuse double layer (layer Gouy-Chapman) are formed, which have a high conductivity in opposition to the low conductivity of the surrounding material. Charge movement through these layers is relatively easy [17]. In this way, a current flow is possible between the nanoparticles. In another paper [18], it was noted that the significant interfacial polarization in conventional polymers is mitigated in nanocomposites, where a short-range highly immobilized layer develops near the surface of the nanoparticle. This layer affects a much larger region surrounding the nanoparticle in which conformational behavior and chain kinetics are greatly altered. It is that this interaction zone is important for the material property modifications, especially if the curvature of the nanoparticles approaches the chain conformation length of the polymer.

Lewis based his approach on O' Konski's model and on the consideration of the double layer. Lewis' model differed from that of Tanaka, in that Lewis proposed just two layers whereas Tanaka proposed in fact four (multi-core model based on bonded layer, bound layer, loose layer and double layer overlapping with the other three layers). Tanaka 's model is similar to that of Lewis only in that last double layer. Tanaka postulated that defects and impurities are likely to be present on the outer layer in his proposed multi-core model [9]. Such defects and impurities may act as traps, which will be distributed in shallower energy levels than traps originally present in base materials. Deep traps are likely to be formed in the second layer of the multi-core model. This may mean the increase in space charge because the deeper traps will trap carriers only after all shallow trap levels have been filled up [19]. Tanaka elaborated this approach in a further paper, where he remarked that treeing is affected by such deep traps. According to his approach, treeing is attributed to accelerated electrons passing between neighboring nanoparticles colliding with interfaces between the polymer and the nanofillers [20]. Nanoparticles - because of their extended surface area - change the very nature of the polymer altering the depth and density of trap sites, reducing in this way charge carrier mobility and energy [7].

It is true that as the particles become smaller and smaller, the role of interfaces becomes more important. A very important point mentioned in [21], is the following: that an improvement in breakdown strength of nanocomposites in comparison with conventional polymers is more evident in medium- or long-term degradation properties. The aspect ratios of nanoparticles and the interfacial properties are crucial for the electrical behavior of a nanocomposite.

The role of interfaces (and consequently of interphase, which consists of polymer chains having different morphology from that of the surrounding uninfluenced polymer) was also emphasized in [22, 23], where it was shown that nanocomposites with higher interphase content have a higher resistance to tracking and erosion than nanocomposites with lower interphase content.

In [24], the role of interfaces is also emphasized. Interfacial strengthening between silica nanoparticles and the organic polymer (epoxy resin) through the silane coupling help reduce the mobility of charge carriers and thus increase the partial discharge resistance. The authors give also another interesting approach of the improvement of the electrical behavior, namely that the nanoparticles fill the space thus decreasing the volume of epoxy resin. A different approach is mentioned in [25], where photos of nanocomposite samples were taken showing in detail the dispersion of nanoparticles and their concentration. The techniques used were the TEM (Transmission Electron Microscopy), AFM (Atomic Force Microscopy) and XDC (Xray Disc Centrifuge). Nanoparticles were clearly shown and agglomerations of particles were also spotted.

The role of interfaces is also emphasized in [26], where is pointed out that nanofillers provide large interface density but low trapping efficiency due to the better quality of polymernanograin interfaces. In this same paper, it is also stated that "... nanofiller dispersed in the microcomposite material forms plaques between the micro-sized particles providing an additional barrier to PD propagation", in agreement with previous results [27]. In [28], a highly exciting aspect is reported, namely, that there is an optimum value of filler concentration for each particle size of mica. In other words, the electrical behavior is determined not only by the percentage of contained nanoparticles.

\section{TSAGAROPOULOS' NANOCOMPOSITE MODEL}

Tsagaropoulos' model is analyzed in [8]. It assumes two basic layers around a nanoparticle, an inner tightly bound layer in which polymer motion is severely restricted, and another intermediate layer which is more loosely bound. At the first layer, at a distance of 1 to 20 Angstrom from the nanoparticle surface, the polymer is physically (if not chemically) adsorbed and its dynamics is slowed down as a consequence of this Therefore, it is generally thought to be tightly bound. At larger 
distances of about 25 to 90 Angstrom from the nanoparticle surface, the polymer is believed to be less tight and perform an intermediate dynamics; this layer is more loosely bound [29]. In [30], a third layer is also assumed, that of the unrestricted bulk polymer. The gist of Tsagaropoulos' model is the morphology of the polymer around the filler particles. It is, in other words, the sequence of events accompanying the incorporation of increasing amounts of silica particles in the polymer. This results in a decrease of the average interparticle distance d. Layers of polymer are tightly bound to nanoparticles. The model deals in principle with the two glass transition temperatures in nanofilled polymers. The polymer chains capable of participating in the second glass transition will be called polymer of reduced mobility or loosely bound polymer. In [8], the critical percentage of nanoparticles is put up to $10 \%$, in all probability because it is at this percentage where the average interparticle distance has a 'critical' value $d_{\text {cr. }}$ As the average interparticle distance decreases further, with the incorporation of more filler particles, the mobility restrictions become so severe that the loosely bound polymer is gradually transformed to tightly bound. The volume fraction of loosely bound polymer decreases, resulting in a decrease in the area of the second tan $\delta$ peak. On the contrary, the volume fraction of tightly bound polymer increases. As the interparticle distance decreases, it is the most restricted regions of loosely bound polymer which are transformed first into tightly bound polymer. The regions with the highest $\mathrm{Tg}$ will be eliminated earliest as filler content increases, resulting in an actual decrease of the second Tg. At lower filler content, the amount of the immobilized polymer around the particles is small, allowing for sufficiently strong interactions between the loosely bound polymer and the particles. As the amount of immobile polymer increases at higher nanoparticle contents, such interactions will become weaker. Consequently, as the immobile polymer does not restrict the chain mobility as efficiently as the nanoparticles, the second $\mathrm{Tg}$ decreases. Eventually, with a very high nanoparticle content (in [8], the authors mention contents of more than $50 \mathrm{wt} \%$ ), the average interparticle distance will be much smaller than $d_{c r}$, with the result that nearly all polymer chains are immobilized.

Explaining Tsagaropoulos' model in other words, one can note that the loosely bound polymer exhibits its own glass transition, whereas the tightly bound does not participate in the glass transition. At lower concentrations of nanoparticles, the interparticle distances are large and the mobility of the polymer next to the tightly bound layers is not influenced. Such regions cannot form a second glass transition, despite the fact that the temperature of the first glass transition decreases. By the nanoparticle concentration, the interparticle distances are reduced. When the loosely bound layers start to overlap - and a critical interparticle distance is reached - they can exhibit their own glass transition. When the nanoparticle concentration increases further, the polymer regions with reduced mobility decrease but the immobilized regions increase. Consequently, the loosely bound layers are converted into tightly bound layers and thus, there is a reduction of the second glass transition temperature.

Higher filler loading implies smaller interparticle distances, the volume fraction of the loose polymer layer is reduced and the nanoparticles themselves start acting as barriers to the flow of current between the electrodes [31]. The focus of Tsagaropoulos' model is on the influence of filler particles on the mobility of polymer chains [32]. Tsagaropoulos' model claims that the discrete bound layer can result in a second glass transition temperature but work on thin films did not point to a discrete layer of affected material but to a far field effect [33]. To emphasize this point, in yet another publication, it was remarked that the two-layer model by Tsagaropoulos does not embody the physics of the whole situation [34]. In the latter publication, it was claimed that the mere presence of regions of modified mobility in the proximity of nanoparticles cannot explain the glass transition temperature results. The smallest interparticle spacings, which would percolate first, would dominate the behavior. Such interaction effects apply also in the case of functionalized nanoparticles, the only difference being that in close vicinity to the nanoparticles, the regions have reduced mobility. The glass transition process in restricted geometries requires the interaction of near surface regions of altered mobility. Although the authors of [34] differentiate from Tsagaropoulos' model, they also use terms such as 'regions of reduced mobility', which remind us well of Tsagaropoulos' model.

Justification to a certain extent of Tsagaropoulos' model is mentioned in [30], where NMR data support it, since as was mentioned in a previous paper, ' $\ldots$ the adsorption layer differing in mobility from bulk PDMS could be detected just above the glass transition temperature in systems filled with hydrophobic Aerosil' [35]. Further support for this model was given in [29], where faster processes correspond to bulk polymer whereas slower processes are interpreted in terms of tightly bound polymer chains, whose segmental dynamics are slowed down w.r.t. bulk dynamics as a consequence of the interaction with the silica nanoparticle surface. Further support is offered in [36], where Dynamic Mechanical Thermal Analysis suggests that polymer chain motion in polymer electrolytes is affected by the presence of nanoparticle surfaces, i.e. glass transition temperature increases by increasing the percentage of nanoparticles. Additional support of Tsagaropoulos' model came relatively recently in [37], where the authors investigating polymer blends (PP/EPR)/W/PEP and $(\mathrm{PP} / \mathrm{EPR}) / \mathrm{S} / \mathrm{PEP}$, observed a second peak of relaxation at -38 and $-36 \mathrm{C}$ in the presence of PEP copolymer. The authors of [37] explained the observation by using Tsagaropoulos' model, i.e. that the strongly bound layer, immediately surrounding the nanoparticle does not participate in the glass transition, the second loosely bound interfacial layer is responsible for the second glass transition and the quasi-bulk polymer remains unaffected by the nanoparticle. Echoes of support of Tsagaropoulos' model can also be found in [38], where the authors, by investigating nanocomposites consisting of mixtures of PEEK (poly(ether-ether-ketone))and nanoparticles, contributed the increase in microhardness to the dominant role of increased crystallinity and PEEK morphology in the vicinity of the nanoparticles. Tsagaropoulos' model is commented favorably in [39], where it is pointed out that shifts in $T_{g}$ to either higher or lower temperatures are observed with nanocomposites by appropriately tuning the interactions between polymer and nanoparticles. The magnitude of the 
shifts is dependent on the relative quantities of the polymer and the nanoparticles; a greater nanoparticle concentration results in a more dramatic effect. Moreover, the viscoelastic response of the polymer matrix composite is altered significantly by the presence of silica nanoparticles in comparison to that of the bulk polymer, as was pointed out in [40]. The authors explain this with the aid of Tsagaropoulos' model. In studying the role of various nanoparticles on the electrical properties of epoxy resin, other researchers explained the decrease of permittivity of nanocomposites by considering that the interaction between nanoparticles and polymer matrix reduces the mobility of epoxy chain in the bulk material, which results in a reduction of the effective permittivity of epoxy nanocomposites. The thin immobile nano-layers, which are formed, restrict the mobility of the epoxy chain. As the loading concentration increases, more immobile layers are formed and the mobility of the epoxy chain decreases continuously, resulting thus in a reduction of the permittivity of the nanocomposite [41].

Further support for Tsagaropoulos' model can also be traced in [42], where the broadening of the $\tan \delta$ peak to higher temperatures as well as the decrease of the magnitude of $\tan \delta$ peak are attributed, by the authors, to the variation in interaction between PAN (polyacrylnitrile) and ATO (antimony-doped tin oxide). The motion of PAN molecules closer to the nano-ATO particles would be more constrained than those farther away from it. Echoes of Tsagaropoulos' model can also be found in [43], where with a high fraction of nanoparticles offers a lower degree of crystallization might occur, since the mobility of the polymer matrix chain segments will decrease during the period of crystallization. In [44], the authors seem to accept Tsagaropoulos' model claiming that "for the PC/MWNT composite, the higher $\tan \delta$ peak becomes broader, which may be considered that the mobility of the polymer chain becomes more restricted by the MWNT ... [possible explanation is that] ... the phase separation morphology model according [to which] the lower tan $\delta$ peak of the polymer composites corresponded to the Tg of the polymer matrix, and the higher tan $\delta$ peak of the polymer composites corresponded to the $\mathrm{Tg}$ of the confined polymer chain by the filler". Also in [45], a second thermal transition above the glass transition which was noted for samples in excess of $20 \mathrm{wt} \%$ fumed silica, was attributed to the polymer closely interacting with the silica filler, i.e. what is termed bound polymer. Relatively recently, it was pointed out that nanofillers can constrain the mobility of polymer chains as well as their relaxation spectra, which can change the glass transition temperature and modulus of the matrix [46].

Concluding, one may say that Tsagaropoulos' model indicates the presence of two tan $\delta$ peaks, one related to the base polymer and the other - which occurs at higher temperatures is due to polymer regions of reduced mobility because of the nanoparticles. As a general comment, one may say that Tsagaropoulos' model, despite some weaknesses, is generally accepted as a nanocomposite model explaining various aspects of nanocomposite behavior, especially those having to do with the glass transition temperature.

\section{TANAKA'S NANOCOMPOSITE MODEL}

Tanaka's model consists of a multicore description for nanoparticles $[9,10]$. It bears also the name 'multi-core' model since it considers more than two layers. Tanaka working independently of Tsagropoulos, proposed another model. There is a bonded layer around the nanoparticle (first or innermost layer), a bound layer (second layer), a loose layer (third layer) and an electric double layer overlapping the above three layers. The first layer corresponds to a transition layer tightly bonded to both inorganic and organic substances by coupling agents, such as silane. Its thickness is postulated to be of about $1 \mathrm{~nm}$. The first layer is tied by ionic, covalent, hydrogen and van der Waals bondings. The second layer is an interfacial region consisting of a layer of polymer chains strongly bound and/or interacted to be first layer and the surface of the inorganic particle. The thickness of this layer is between 2 and $9 \mathrm{~nm}$. These values depend on the strength of the polymer-particle interaction. Obviously, the stronger the interaction, the larger the polymer fraction. Chain mobility and crystallinity are deeply involved. The former is directly related to glass transition temperatures. The average chain conformation can be altered and/or the type and degree of crystallinity can change. The third layer is a region of loosely coupling and interacting to the second layer. The loose layer has different chain conformation, chain mobility and even free volume or crystallinity from the polymer matrix. This layer is of several tens of nm thick. The fourth layer, the electric double layer, forms a long distance dipole. This will affect electrical conduction and dielectric properties in the low frequency region. As is indicated in [10], a nanoparticle is charged positively or negatively when a polymer has mobile charge carriers, which are distributed in the interface so that the counter charges with the opposite polarity are diffused outward from the contact surface to the Debye shielding length corresponding to the Couy-Chapman diffuse layer in which charge decays exponentially according to the Born approximation. In other words, Tanaka's model considers that nanoparticles are positively or negatively charged, taking into account that are inserted into polymeric materials which end to be either positively or negatively charged. Such charging may in some ways have an effect on discharge treeing paths. Simulation results until now give some good grounds to Tanaka's model. As was indicated previously, electrical tree paths in a nanocomposite go through the polymer and not through the nanoparticles [47, 48]. Treeing paths may propagate through the polymer and/or they may touch nanoparticles and circumvent them. Simulation data show that in no case treeing paths go through the nanoparticles. Although one may say that these are just simulation results, i.e. they do not take into account all possible involved parameters, it is undeniable that they - at least - partially simulate realistic conditions. Also in [49], it was indicated that in absence and/or in presence of homocharges/heterocharges, nanoparticles act as elementary barriers to the propagation of electrical trees. Moreover, simulations with homocharge presence show that the tree propagation stops at a certain stage. This although it may not explain the gist of Tanaka's model, it shows, however, that with charges of the same polarity the tree growth stops. Homocharges and scattering mechanism (due to nanoparticles 
and the interfacial regions) contribute to the enhancement of the dielectric properties of nanocomposites [50]. Evidence, that converges with the simulation results presented in [47, 48], was published recently, where was remarked that layered montmorillonite particles have the strongest effect on slowing down the propagation of electrical treeing in LDPE [21]. In the latter paper, it is also pointed out that the strongest benefit from nanostructuration is gained in the mid-term performance of the material. Furthermore, other researchers observed that nanofillers relate to the excellent resistance to partial discharges and electrical treeing in the cases of epoxy with alumina and of epoxy with silica nanocomposites [51], whereas others still claim that because the distances between nanoparticles are very small, they hinder the movement of charge carriers and thus the dielectric strength increases [52]. In another paper [53], the authors present photographic evidence indicating that tree channels extend between nanoparticles and expand in a direction perpendicular to tree length to contact nanoparticles. This means that trees interact with nanoparticles when they become thicker. This presumably suggests that trees are modified through the applied field and in turn they modify the nanocomposite structure.

Tanaka's model was extensively discussed in [54], where it was remarked that the third layer will have a dominant effect on the overall performance of the nanocomposite, as being much larger than the first two layers. With high nanoparticle percentage, about $50 \%$ of the total volume will be affected and one may assume that it is possible that also the shell layer interfaces will overlap. This point is somehow shown, albeit with all reservations of the simulation parameters, in [47-49], where treeing paths penetrate through the polymer. In the aforementioned publications, the tree propagation is shown in a nanocomposite with well defined nanoparticles and a space charge density of $40 \mathrm{C} / \mathrm{m}^{3}$. Homocharge was considered. The tree propagation stopped with homocharges present. Tanaka's model was discussed in [55-57], where the authors used an analogy of the model to explain the percolation of charge carriers through overlapping water shells. In [55-57], it was claimed that the inner layer of water may surround the nanoparticle and the second water layer to be dispersed but sufficiently concentrated to be conductive. It was considered that the inner and outer layers are likely to provide a channel for charges and carriers. Once the water shell around a nanoparticle can overlap with the others, charges and carriers may move with through the interaction zone between neighboring particles. Tanaka's model in fact, in the above publications, helped to study the electrical properties of epoxy resin nanocomposites as a function of hydration.

In another publication, the authors tend to agree with Tanaka's model and with Tanaka's estimate of the interaction zone as a fraction of a $\mathrm{nm}$ when the coupling of inorganic surface with the polymer matrix increases by using silane [58]. The authors of [58], however, put more emphasis on the intensity and specificity of the chemical activity - which will affect the polymerization of the interface - and not so much on the thickness of this zone. Another researcher, in [59], seems to accept Tanaka's model when he discusses overlapping zones between the nanoparticles and complete percolation through interaction zones and volumetric concentration. In the same publication, he carries on to ask pertinent questions regarding the nature of interaction zone around the nanoparticles, the layers which comprise the interaction zones and their thicknesses.

Tanaka's model is much more recent than Tsagaropoulos' model. It was positively received by the scientific community since it offers plausible explanations as to the some aspects of the electrical behavior of nanocomposites. It must, however, be noted that more experimental results, and particularly photographic evidence, are needed in order to fully verify it. Optical microscopy as well as SEM are needed to exactly trace the discharge and/or treeing paths in nanocomposites. This point is also stressed below. Good reliable photographs should be obtained by cutting the nanocomposite in very thin slices. This is a most daunting task and by no means an easy one.

A further point to be mentioned is the crossover phenomenon, observed under certain conditions, i.e. the fact that tree propagation is different between base epoxy resin and its nanocomposite counterpart under different voltage conditions. It was observed that at lower voltages, the tree propagation speed for nanocomposites is lower than that for base epoxy resin. On the contrary, at higher voltages, the tree propagation speed is higher in nanocomposite epoxy resin than in base epoxy resin [6]. Although an explanation was offered, namely that an erosion type of degradation takes place under lower voltages whereas a progressive type of degradation takes place at higher voltages, further work is needed, bearing in mind Tanaka's model, regarding the explanation of the above mentioned crossover phenomenon.

\section{THE TWO MODELS: SIMILARITIES AND DIFFERENCES}

Regarding interpretational possibilities, Tanaka's model is not different from Tsagaropoulos' model. Needless to say that both models are indebted to the original Lewis' publication [1]. Both models tend to assume an inner bonding layer, strongly attached to the nanoparticle, they differ, however, somehow (but not radically) in the way they perceive the reaction to other nanoparticles and/or to the rest of the polymer. Their major difference is in the number of assumed layers, and not so much as to what these layers may do. Tanaka's model seems to be more complete in that it considers in some detail the workings of the polymer matrix/nanoparticle interface. Both models try to explain the second glass transition temperature. Both models assume that the interparticle region is the weak link in the polymer - nanoparticle system. Tsagaropoulos' model tends to explain rather well the glass transition temperature variation when nanoparticles are added to a conventional polymer. Tanaka's model also tries to explain the glass transition temperature variations by claiming that "... improvement in glass transition temperature must originate from the formation of the second and third layers of the multi-core model. It indicates that fillers and matrices are rather tightly bonded through these layers" [9].

Tsagaropoulos' model refers more to glass transition temperature data without any elaboration regarding the electrical treeing and breakdown strength of nanocomposites. Tanaka's model tackles precisely these issues. Although the two aforementioned models differ in their number of layers, 
their respective thicknesses and their possibility of interpretation of various phenomena, they both refer to layers surrounding a nanoparticle and they both explain why with the addition of nanoparticles there is a marked improvement in the properties of conventional polymers. Recent simulation results [47-49] indicate that electrical treeing goes through the polymer matrix, avoiding thus the nanoparticles. This is an indication of validity of both models but not yet a proof. The indication seems to be stronger in Tanaka's model (which assumes charged nanoparticles), since the simulations show that - in the presence of homocharges - trees propagate through the polymer matrix. One may well argue that homocharges are not the same and they are not perceived as the same as the charged nanoparticles in Tanaka's model. Tanaka's model assumes an electric double layer for each nanoparticle, and it also assumes that this is the result of triboelectricity. The answer to such claims is that, although homocharges are something different, they also assume the same polarity charges around the nanoparticles and in this respect, their end result will be the same. These simulation data, however, do not go against Tsagaropoulos' model since this model is also based on tightly bound layers hindering breakdown events and thus strengthening the nanocomposite.

It has to be clear that the above two models are not by any means exhausted in the references cited here. Recent research indicated that, with the aforementioned models justified to a certain extent, higher stresses and a reduction in insulation thickness would be possible $[60,61]$. In the context of the present work, we tried to approach both models, their respective merits and to point out some aspects in need of further research.

\section{PROPOSALS FOR FURTHER RESEARCH}

What is missing for the time being, is not so much experimental data regarding the improvement of the electrical properties of nanocomposites w.r.t. the conventional composites, but more photographic evidence. In this respect, SEM photographs (or TEM photographs), among others, may indeed give information as to the directions followed by treeing and/or discharge paths in nanocomposites. They may indicate whether such paths avoid the nanoparticles. SEM evidence for the time being confirms that nanoparticles act as a sort of barriers opposed to the advancement of electrical treeing. SEM evidence confirms that discharge and treeing paths go round the nanoparticles. More evidence, however, is needed. This task is by no means simple, since it is difficult to obtain clear treeing paths round nanoparticles.

Physical models regarding the treeing path have been proposed [62]. Such models propose that trees will dwell at the nanoparticle surface and try to propagate through the nanoparticle-polymer interface. The nanoparticles would create a hindrance to growth, and they will prevent trees to grow in rather straightforward directions. Trees will propagate from nanoparticle to nanoparticle through the polymer. Consequently, the tree structure will be dense and zigzag. Reference [62] implies that trees propagate through the weaker insulating material and not through the nanoparticles. Such models, however, no matter how plausible explanations they may offer, have to be supported by evidence and this evidence can be given by sophisticated photographic techniques. Photographic techniques can be either SEM or TEM, which may shed light to the inner workings of pre-breakdown and breakdown phenomena in nanocomposites. One cannot enough overstress that such photographs are very difficult to obtain since, in order to get such photographs a cutting of the samples with more than surgical precision is required.

Needless to say that, the two aforementioned models have to be tried in various kinds of nanocomposites. It is only through the variety of nanoparticle-polymer combinations that more insight as to the workings of the improvement of the nanocomposite properties may be gained. Moreover, the aforementioned models should also be tried with various nanoparticles concentrations as well as with various nanoparticle dimensions in order to check their validity. Generally speaking, there is an optimum percentage (wt\%), depending on the base polymer matrix and the nanoparticles, beyond which the electrical properties of the nanocomposite cannot be improved (not to say, they worsen). What are the interpretational possibilities of the two aforementioned models regarding the optimum percentage of nanoparticles? Are the so-called agglomerations of nanoparticles - as the nanoparticle percentage goes up - a reasonable and adequate explanation for the optimum percentage of nanoparticles?

On the other hand, from the side of simulations, more refined simulations have to be performed which should closely resemble to the real trees. In that, a better evaluation of the various parameters has to be taken into account, i.e. a better evaluation of the electric field distribution inside a nanocomposite. In other words, a better evaluation has to be made regarding the influence of the nanoparticles on the very existence of the electric field in the nanocomposite. How the nanoparticles affect the electric field? What is the effect of their proximity on the electric field distribution? Regarding some more general questions, how a proposed model may interpret not only electrical trees inside the main insulation volume but also the influence of surface discharges on a nanocomposite? The case of surface discharges is most interesting since according to previous work, nanoparticles play a dominant role in determining the surface flashover of nanocomposites and their agglomerations on the surface of the nanocomposite tend to hinder further surface degradation. Consequently the role of nanoparticle agglomerations (which in the bulk of the nanocomposite may have a rather negative effect), has to be clarified in the light of relatively recent work [63]. Further recent research - on water droplets on nanocomposite surfaces points out to the importance of surface phenomena on nanocomposite surfaces $[64,65]$. It would be scientifically highly interesting if the models proposed by Tsagaropoulos and Tanaka can be tested also against surface discharge phenomena, which doubtless cause significant degradation. A step even further would be to test these models w.r.t. the thermal and mechanical properties of polymer nanocomposites $[66,67]$.

A further point to be researched and discussed in the future is the following: given that nanocomposite polymers may be used also for outdoor applications, what are the interpretational 
possibilities of the aforementioned models as to the effect of water and/or water diffusion in nanocomposites? How functionalization (i.e. the chemical adjustment of nanoparticles to the better bonding with the base polymer matrix) of the nanoparticles can hinder water diffusion? Can the nanocomposite models - described in the present paper - take into account such phenomena?

\section{CONCLUSIONS}

In this paper, a comparison between two well known models is being made. Both models have their own merit, both were influenced by the original contribution by Lewis, both are supported by some experimental evidence and recent simulation data. The models, Tsagaropoulos' model and Tanaka' s model, have their own explanatory power and they are based on the idea of more and less well bonded layers around nanoparticles in the polymer matrix. More research has to be carried out, however, regarding the photographic evidence of the treeing and/or discharge paths in nanocomposite polymers. Such photographs have to be either SEM or TEM. The validity of the models should also be tested regarding the thermal and mechanical properties of the said materials, since in high voltage applications it is very often the case of combined electrical, thermal and mechanical stresses.

\section{ACKNOWLEDGMENTS}

One of the authors (MGD) wishes to express his gratitude to Professor Toshikatsu Tanaka of Waseda University, Graduate School of Information, Production and Systems, for having invited him as Visiting Scholar in his laboratory during the academic year 2008-09 and having introduced him to the subject of nanocomposites.

\section{REFERENCES}

[1] T. J. Lewis, "Nanometric dielectrics", IEEE Trans. Diel. Electr. Insul, Vol. 1, pp. 812-825, 1994

[2] M. Takala, H. Ranta, J. Pelto, S. Virtanen, V. Koivu, M. Petterson, K. Kannus, "Dielectric properties of polypropylene-silica nanocomposites", Nordic Insul. Symp., pp. 31-35, Goeteborg, Sweden, June 15-17, 2009

[3] S. Zhao, L. S. Schadler, H. Hillborg, T. Auletta, "Effect of interfacial strength on mechanichal properties of $\mathrm{Al}_{2} \mathrm{O}_{3} /$ epoxy nanocomposites", Nordic Insul. Symp., pp. 41-44, Cothenburg, Sweden, June 15-17, 2009

[4] R. Kochetov, T. Andritsch, U. Lafont, P. H. F. Morshuis, J. J. Smit, "The thermal conductivity in epoxy - Aluminum nitride and epoxy Aluminum oxide nanocomposite systems", Nordic Insul. Symp., Goeteborg, pp. 27-30, Sweden, June 15-17, 2009

[5] See for example the whole issue of IEEE Trans. Diel. Electr. Insul., Vol. 15 , No. 1 , February 2008

[6] J. K. Nelson (editor), Dielectric polymer nanocomposites, Eds. Springer, Heidelberg, 2010

[7] M. F. Frechette, A. Vijh, M. L. Trudeau, L. Utracki, A. Sami, E. David, C. Laurent, P. Morshuis, T. Andritsch, R. Kochetov, A. Vaughan, J. Casteellon, D. Fabiani, S. Gubanski, J. Kindersberger, C. Reed, A. Krivda, J. Fothergill, S. Dodd, F. Guastavina, H. Alamdari, "Nanodielectrics: A panacea for solving all electrical insulation problems?", 2010 Int. Conf. Solid Diel., pp. 130-158, Potsdam, Germany, July 4-9, 2010

[8] G. Tsagaropoulos, A. Eisenberg, "Dynamic mechanical study of the factors affecting the two glass transition behavior of filled polymers. Similarities and differences with random ionomers", Macromolecules, Vol. 28, pp. 6067-6077, 1995
[9] T. Tanaka, "Dielectric nanocomposites with insulating properties", IEEE Trans. Diel. Electr. Insul., Vol. 12, No. 5, pp. 914-928, 2005

[10] T. Tanaka, "Polymer nanocomposites as HV insulation: Superiority and expectation', Proc. XVth Int. Symp. High Volt. Eng., Ljubljana, Slovenia, August 27-31, 2007

[11] M. G. Danikas, "On two nanocomposite models: Differences, similarities and interpretational possibilities regarding Tsagatopoulos' model and Tanaka's model", J. Electr. Eng., Vol. 61, No. 4, pp. 241246, 2010

[12] D. Kind, H. Kaerner, High-voltage insulation technology, Eds. Fr. Vieweg \& Sohn, Braunschweig/Wiesbaden, Deutschland, 1985

[13] D. Koenig, Y. N. Rao, Teilentladungen in Betriebsmitteln der Energietechniek, Eds. Vde verlag gmbh, Berlin und Offenbach, Deutschland, 1993

[14] M. Roy, J. K. Nelson, R. K. MacCrone, L. S. Schadler, C. W. Reed, R. Keefe, W. Zenger, "Polymer nanocomposite dielectrics - The role of the interface”, IEEE Trans. Diel. Electr. Insul., Vol. 12, No. 4, pp. 629-643, 2005

[15] T. Tanaka, G. Montanari, R. Mulhaupt, "Polymer nanocomposites as dielectrics and electrical insulation - perspectives for processing technologies, material characterization and future applications", IEEE Trans. Diel. Electr. Insul., Vol. 11, No. 5, pp. 763-784, 2004.

[16] J. K. Nelson, Y. Hu, "Nanocomposite dielectrics - Properties and implications", J. Phys. D: Appl. Phys., Vol. 38, pp. 213-222, 2005

[17] J. K. Nelson, J. C. Fothergill, "Internal charge behaviour of nanocomposites", Nanotechnology, Vol. 15, No. 5, pp. 586-595, 2004

[18] J. K. Nelson, J. C. Fothergill, L. A. Dissado, W. Peasgood, "Towards an understanding of nanometric dielectrics", Ann. Rep. Conf. Electr. Insul. Diel. Phen. (CEIDP), pp. 295-298, Mexico, Oct. 20-24, 2002

[19] S. Das, N. Gupta, "Study of space charge characteristics in epoxy resin and its nanocomposites", 2010 Int. Conf. Solid Diel. (ICSD), pp. 235238, Potsdam, Germany, July 4-9, 2010

[20] T. Tanaka, "Buds for treeing in epoxy nanocomposites and their possible interaction with nanofillers", 2010 Int. Conf. Solid Diel., pp. 159-162, Potsdam, Germany, July 4-9, 2010

[21] F. Guastavino, A. Dardano, S. Squarcia, P. Tiemblo, J. Guzman, N. Garcia, "LDPE nanocomposites: A study about breakdown strength and voltage endurance", Proc. 2010 Int. Conf. Cond. Monit. Diagn. (CMD), pp. 503-506, Tokyo, Japan, September 6-11, 2010,

[22] S. Raetzke, J. Kindersberger, "Role of interphase on the resistance to high-voltage arcing, on tracking and erosion of silicone $/ \mathrm{SiO}_{2}$ nanocomposites", IEEE Trans. Diel. Electr. Insul., Vol. 17, No. 2, pp. 607-614, 2010

[23] S. Raetzke, J. Kindersberger, "Resistance to high voltage arcing and the resistance to trackning and erosion for silicone/ $\mathrm{SiO}_{2}$ nanocomposites", Proc. $16^{\text {th }}$ Int. Symp. On High Volt. Eng., Paper F-10, South Africa, 2009

[24] Chang-Hoon Lee, Jae-Hun Park, "The partial discharge resistance of epoxy-nano-and-micro composites", Trans. Electr. Electron. Mater., Vol. 11, No. 2, pp. 89-91, 2010

[25] E. Bretsnajdrova, L. Svoboda, J. Zelenka, "Determination of particle shape and size distribution of model types of nanomaterials", J. Electr. Eng., Vol. 61, No. 5, pp. 302-304, 2010

[26] D. Fabiani, G. C. Montanari, A. Krivda, L. E. Schmidt, R. Hollertz, "Epoxy based materials containing micro and nano sized fillers for improved electrical characteristics", 2010 Int. Conf. Solid Diel., pp. 212215, Potsdam, Germany, July 4-9, 2010

[27] A. Cavallini, D. Fabiani, G. C. Montanari, L. Testa, "Extraction of aging markers for nanstructured epoxy resin aged under surface discharges", IEEE Electr. Insul. Conf, pp. 387-391, Montreal, Canada, 2009

[28] A. Ersoy, H. R. Hiziroglu, "Electrical breakdown of polyurethane-based nanocomposites", 2010 Int. Conf. Solid Diel., pp. 216-218, Potsdam, Germany, July 4-9, 2010

[29] A. Triolo, E. Lo Celso, F. Negroni, V. Arrighi, H. Qian, R. E. Lechner, A. Lechner, A. Desmedt, J. Pieper, B. Frick, R. Triolo, "QENS investigations of filled rubbers", Appl. Phys. A: Mater. Sci. and Process., Vol. 74, pp. 490-492, 2002 
[30] V. Arrighi, I. J. McEwen, H. Qian, M. B. Serrano Prieto, "The glass transition and interfacial layer in styrene-butadiene rubber containing silica nanofiller", Polymer, Vol. 44, No. 20, pp. 6259-6266, 2003

[31] S. Singha, M. J. Thomas, "Dielectric properties of epoxy nanocomposites", IEEE Trans. Diel. Electr. Insul., Vol. 15, No. 1, pp. 12-23, 2008

[32] L. A. Berglund, "Reology of polymer nanocomposites - Are there unique effects for exploitation?", Annual Transactions of the Nordic Rheology Society, Vol. 14, 2006

[33] P. M. Ajayan, L. S. Schadler, P. V. Braun, Nanocomposite Science and Technology, Eds. Wiley-VCH Verlag, Weinheim, Germany, 2003

[34] A. Bansal, H. Yang, C. Li, K. Cho, B. C. Benicewicz, S. K. Kumar, L. S. Schadler, "Quantitative equivalence between polymer nanocomposites and thin polymer films", Nature Mater., Vol. 4, pp. 693-698, 2005

[35] V. M. Litvinov, H. M. Speiss, "H NMR study of molecular motions in polydimethylsiloxane and its mixtures with aerosols", Makromol. Chem., Vol. 192, No. 12, pp. 3005-3019, 1991

[36] J. B. Kerr, Y. B. Han, G. Liu, C. Reeder, J. Xie, X. Sun, ”Interfacial behavior of polymer electrolytes", Lawrence Berkley National Laboratory, Paper LBNL-53141, 2003

[37] N. Mnif, V. Massardier, T. Kallel, B. Elleuch, "New (PP/EPR)/nano$\mathrm{CaCO}_{3}$ based formulations in the perspective of polymer recycling. Effect of nanoparticles properties and compatibilizers", Polym. Advanced Technol., Vol. 21, No. 12, pp. 896-903, 2010

[38] R. K. Goyal, A. N. Tiwari, Y. S. Negi, "Microhardness of PEEK/ceramic micro- and nanocomposites: Correlation with HalpinTsai model”, Mater. Sci. and Eng.: A, Vol. 491, pp. 230-236, 2008

[39] F. W. Starr, T. B. Schroeder, S. C. Glotzer, "Effects of a nano-sized filler on the structure and dynamics of a simulated polymer melt and the relationship to ultra-thin films", Physical Review E, Vol. 64, No. 2, pp. 021802-1 - 021802-5, 2001

[40] F. T. Fisher et al., "Spectral response and effective viscoelastic properties of MWNT-reinforced polycarbonate", Adv. Composites Lett., Vol. 13, No. 2, pp. 105-111, 2004

[41] Q. Wang, G. Chen, A. S. Alghamdi, "Influence of nanofillers on electrical characteristics of epoxy resins insulation", 2010 Int. Conf. Solid Diel., pp. 263-266, Potsdam, Germany, July 4-9, 2010

[42] Wei Pan, Handao Zou, "Characterization of PAN/ATO nanocomposites prepared by solution blending”, Bul. Mater. Sci., Vol. 31, No. 5, pp. $807-811,2008$

[43] M. C. Kuo, L. M. Tsai, J. C. Huang, M. Chen, "PEEK composites reinforced by nano-sized $\mathrm{SiO}_{2}$ and $\mathrm{Al}_{2} \mathrm{O}_{3}$ particulates", Mater. Chem. And Phys., Vol. 90, pp. 185-195, 2005

[44] Y. T. Sung, C. K. Kum, H. S. Lee, N. S. Byon, H. G. Yoon, W. N. Kim, "Dynamic mechanical and morphological properties of polycarbonate/multi-walled carbon nanotube composites", Polymer, Vol. 46, No. 15 , pp. 5656-5661, 2005

[45] S. D. Burnside, E. P. Giannelis, "Nanostrusture and properties of polysiloxane-layered silicate nanocomposites", J. Polym. Sci. Part B: Polym. Phys., Vol. 38, No. 12, pp. 1595-1604, 2000

[46] S. S. Samai, "Role of temperature and carbon nanotube reinforcement on epoxy based nanocomposites", J. Miner. \& Mater. Charact. \& Eng., Vol. 8, No. 1, pp. 25-36, 2009

[47] D. Pitsa, G. E. Vardakis, M. G. Danikas, "Effect of nanoparticles loading on electrical tree propagation in polymer nanocomposites", Proc. 2011 Int. Symp. Electr. Insul. Mater. (ISEIM2011), Paper A3, pp. 9-11, Kyoto, Japan, September 6-10, 2011

[48] D. Pitsa, M. G. Danikas, G. E. Vardakis, T. Tanaka, "Influence of homocharges and nanoparticles in electrical tree propagation under DC voltage application", Archiv f. Elektr. (Electrical Engineering), Vol. 94, No. 2, pp. 81-88, 2012

[49] D. Pitsa, G. Vardakis, M. G. Danikas, M. Kozako, "Electrical treeing propagation in nanocomposites and the role of nanofillers: Simulation with the aid of Celluar Automata", J. Electr. Eng., Vol. 61, No. 2, pp. $125-128,2010$.
[50] R. C. Smith, C. Liang, M. Landry, J. K. Nelson, L. S. Schadler, "The mechanism leading to the useful electrical properties of polymer nanodielectrics", IEEE Trans. Diel. Electr. Insul., Vol. 15, No. 1, pp. 187-196, 2008

[51] Y. Okazaki, M. Kozako, M. Hikita, T. Tanaka, "Effects of addition of nano-scale alumina and silica fillers on thermal conductivity and dielectric strength of epoxy/alumina microcomposites", 2010 Int. Conf. Solid Diel., pp. 279-282, Potsdam, Germany, July 4-9, 2010

[52] I-B Jeong, J-S Kim, H-S Han, Y-S Lee, J-Y Lee, J-Y Shin, J-W Hong, "Influences of filler depending on electrical insulation properties of nano-composite", Proc. 2010 Int. Conf. Cond. Monit. Diagn., pp. 910913, Tokyo, Japan, September 6-11, 2010

[53] T. Iizuka, T. Tanaka, "Effect of nano silica filler size on treeing breakdown lifetime of epoxy nanocomposites", Proc. $9^{\text {th }}$ Int. Conf. Prop. Appl. Diel. Mater., pp. 733-736, Harbin, China, July 19-23, 2009

[54] A. Hajiyannis, G. Chen, "Space charge formation in epoxy resin including various nanofillers", 2008 Ann. Rep. Conf. Electr.Insul.Diel. Phen., pp. 714-717, Canada, October 26-29, 2008

[55] Chen Zou, J. G. Fothergill, S. W. Rowe, "The effect of water absorption on the dielectric properties of epoxy nanocomposites", IEEE Trans. Diel Electr. Insul., Vol. 15, No. 1, pp. 106-117, 2008

[56] C. Zou, M. Fu, J. G. Fothergill, S. W. Rowe, "The influence of water on dielectric behavior of silica-filled epoxy nano-composites and percolation phenomena”, 2007 Ann. Rep. Conf. Electr. Insul. Diel. Phen., Canada, October 14-17, 2007

[57] C. Zou, J. G. Fothergill, S. W. Rowe, "A 'water shell' model for the dielectric properties of hydrated silica filled epoxy nano-composites", 2007 Ann. Rep. Conf. Electr. Insul. Diel. Phen., Canada, October 14-17, 2007

[58] M. F. Frechette, C. W. Reed, "The role of molecular dielectrics in shaping the interface of polymer nanodielectrics", 2007 Ann. Rep. Conf. Electr. Insul. Phen., pp. 279-285, Canada, October 14-17, 2007

[59] J. C. Fothergill, "Ageing, space charge and nanodielectrics: Ten things we don't know about dielectric"“, 2007 Int. Cof. Solid Diel., pp. 1-10, Winchester, UK, July 8-13, 2007

[60] M. G. Danikas, T. Tanaka, "nanocomposites - A review of electrical treeing and breakdown", IEEE Electr. Insul. Mag., Vol. 25, No. 4, pp. 19-25, 2009

[61] E. A. Cherney, "Nanodielectrics applications - Today and tomorrow", IEEE Electr. Insul. Mag., Vol. 29, No. 6, pp. 59-65, 2013

[62] S. Alapati, M. Joy Thomas, "Electrical treeing in polymer nanocomposites", The $15^{\text {th }}$ National Power Systems Conference (NPSC), pp. 352-355, IIT Bombay, December 2008

[63] M. Kozako, R. Kido, T. Imai, T. Ozaki, T. Shimizu, T. Tanaka, "Surface roughness change of epoxy/ $\mathrm{TiO}_{2}$ nanocomposite due to partial discharges", Proc. 2005 Int. Symp. Electr. Insul. Mater., pp. 661-664, Kitakyushu, Japan, June 5-9, 2005

[64] S. C. Kechagia, M. G. Danikas, R. Sarathi, "Water droplets and breakdown phenomena on polymer nanocomposite surfaces under the influence of uniform electric fields", Malaysian Polym. J., Vol. 8, No. 2, pp. $41-47,2013$

[65] A. Bairaktari, M. G. Danikas, X. Zhao, Y. Cheng and Y. Zhang, "Behaviour of water droplets under the influence of a uniform electric field in nanocomposite samples of epoxy resin/ $/ \mathrm{TiO}_{2}$ ", Eng., Technol. Appl. Sci. Res., Vol. 3, No. 5, pp. 511-515, 2013.

[66] R. K. Sahu, "Understanding the electrical, thermal and mechanical properties of epoxy nanocomposites", Ph.D. Thesis, Indian Institute of Technology Madras, Department of Electrical Engineering, Chennai, India, 2007

[67] R. Sarathi, M. G. Danikas, "Understanding the mechanical properties of epoxy nanocomposite insulating materials", J. Electr. Eng., Vol. 60, No. 6, pp. 358-361, 2009 